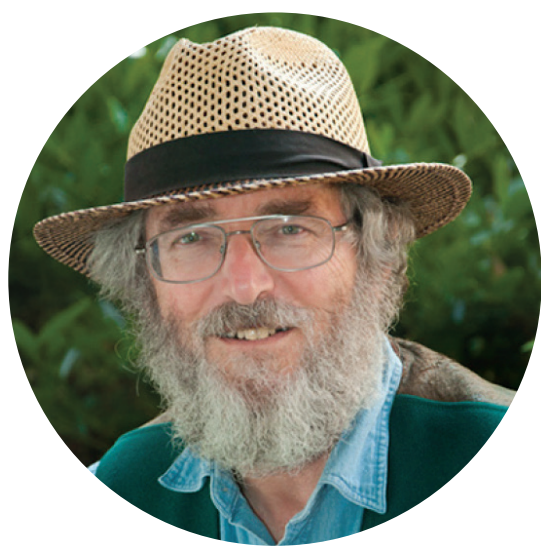

Public health in the 21st century

\title{
Creating healthy cities and communities
}

\section{Trevor Hancock MBBS MHSc} Cite as: CMAJ 2018 February 20;190:
E206. doi: 10.1503/cmaj.180102

Dr. Trevor Hancock is an internationally recognized public health physician. He was one of the creators of the global Healthy Cities and Communities movement, and he cofounded both the Canadian Association of Physicians for the Environment and the Canadian Coalition for Green Health Care. He's a senior editor for the Canadian Journal of Public Health, on the editorial board of Cities \& Health and a columnist for a daily newspaper in Victoria, BC. The Canadian Public Health Association recently recognized his outstanding contributions in the broad field of public health with the R.D. Defries Award.
W

e became an urban species early in the 21st century, with more than half the world's population living in cities. In Canada, four in five live in urban areas. Moreover, North Americans spend $90 \%$ of their time indoors, meaning that the built environment is our most important environment, at least temporally.

The roots of modern-day public health are also urban, having evolved to address the horrifying living conditions of the urban slums in cities of the newly industrializing world. Descriptions of those slums make for sobering reading; life expectancy in the mid-19th century was as low as 17 years in some city slums, with onequarter of all infants dying in the first year; that's not too dissimilar to what is found in the urban slums of many low- and even middleincome countries today. But out of this dreadful situation arose not just a public health movement, but a spirit of social and democratic reform, and the same spirit infused Canada.

In 1914, the Public Health Committee of the federal Commission on Conservation (the equivalent of what today would be a Commission on Sustainable Development) invited Thomas Adams, a leading British town planner, to Canada. He laid down the basis of town planning, and thus the roots of urban planning were closely linked with public health a century ago.

Over the ensuing decades, as the focus of health became more biomedical than environmental and social, these links were lost. However, in the early 1980s, in Toronto, we began to envision what it would take to make Toronto the healthiest city in North America, and, from these small beginnings, the global movement for healthy cities and communities was born.

A new appreciation has emerged for the role of the urban environment in our health. Although we have vastly improved our built environments in the past 150 years or so, we have also created cities and neighbourhoods with new health challenges. Perhaps foremost among these is urban sprawl - a low-density, cardependent, highly segregated urban design - which has many negative impacts on health, as noted in the 2004 book, Urban Sprawl and Public Health, the first to be published on this topic. Much work since then has shown that sprawling suburbia is associated with higher levels of air pollution, greenhouse gas emissions and motor vehicle-related injuries than more dense, walkable, mixed-use urban neighbourhoods. Car-dependency also results in less physical activity and higher rates of obesity, and effectively socially isolates those without a car (e.g., children, some seniors and people with disabilities).

This is why public health has become much more involved in working with local governments and urban planners in recent years to build healthier urban environments. Public health concerns also include inequitable food access in cities lack of access to healthy foods and the excess access to unhealthy food in lowincome neighbourhoods - and inequitable access to parks and benefits of contact with nature.

Indeed, inequalities in health, and in access to the determinants of health, are rampant in urban environments. All over the world, the poor live downwind, downstream, downhill (unless the hills are steep and dangerous, in which case they live uphill). They live in flood plains, close to polluting industries and waste sites, in poor-quality housing and unsafe neighbourhoods that lack clean water, sanitation and access to vital services such as education, health care and public transport.

Of course, reducing these inequalities depends on more than just urban planning. It requires good overall urban governance, which is the focus of the Healthy Cities approach that holds that the central focus of government should be to maximize human development for all of a city's residents. We need to put health and human development at the heart of urban decision-making, with particular attention to reducing health inequalities. That means working in partnership with people who are experiencing those inequalities.

In the 21st century, as we see new threats to urban health arising from converging ecological crises of our own creation, healthy cities and communities must become ecologically sustainable as well as socially just. And so the challenges increase for public health and its allies. 